\title{
Computerized Respiratory Sounds Are a Reliable Marker in Subjects With COPD
}

\author{
Cristina Jácome PT MSc and Alda Marques PT MSc PhD
}

\begin{abstract}
BACKGROUND: Computerized respiratory sounds have shown potential in monitoring respiratory status in patients with COPD. However, the variability and reliability of this promising marker in COPD are unknown. Therefore, this study assessed the variability and reliability of respiratory sounds at distinct air flows and standardized anatomic locations in subjects with COPD. METHODS: A 2-part study was conducted. Part 1 assessed the intra-subject reliability of respiratory sounds at spontaneous and target $(0.4-0.6$ and $0.7-1 \mathrm{~L} / \mathrm{s})$ air flows in 13 out-patients $\left(69.3 \pm 8.6 \mathrm{y}\right.$ old, $\mathrm{FEV}_{1}$ of $70.9 \pm 21.4 \%$ of predicted). Part 2 characterized the inter-subject variability and intra-subject reliability of respiratory sounds at each standardized anatomic location, using the most reliable air flow, in a sample of 63 out-patients $\left(67.3 \pm 10.4 \mathrm{y}\right.$ old, $\mathrm{FEV}_{1}$ of $75.4 \pm 22.9 \%$ of predicted). Respiratory sounds were recorded simultaneously at 7 anatomic locations (trachea and right and left anterior, lateral, and posterior chest). Air flow was recorded with a pneumotachograph. Normal respiratory sound intensity and mean number of crackles and wheezes were analyzed with validated algorithms. Inter-subject variability was assessed with the coefficient of variation, and intra-subject reliability was assessed with the intraclass correlation coefficient (ICC) and Bland-Altman plots. RESULTS: Relative reliability was moderate to excellent for normal respiratory sound intensity and mean number of crackles (ICC of 0.66-0.89) and excellent for mean number of wheezes (ICC of 0.75-0.99) at the 3 air flows. Absolute reliability was greater at target air flows, especially at $0.4-0.6 \mathrm{~L} / \mathrm{s}$. Inter-subject variability was high for all respiratory sound parameters and across locations (coefficient of variation of 0.12-2.22). Respiratory sound parameters had acceptable relative and absolute intra-subject reliability at the different anatomic locations. The only exception was the mean number of crackles at the trachea, for which both relative and absolute reliability were poor. CONCLUSIONS: Respiratory sound parameters are more reliable at an air flow of 0.4-0.6 L/s and are reliable overall at all anatomic locations. This should be considered in future studies using computerized auscultation. Key words: computerized auscultation; respiratory sounds; normal respiratory sounds; crackles; wheezes; chronic obstructive pulmonary disease; reliability. [Respir Care 2015;60(9):1264-1275. (c) 2015 Daedalus Enterprises]
\end{abstract}

\section{Introduction}

COPD is characterized by persistent air-flow limitation that is usually progressive. ${ }^{1}$ The $\mathrm{FEV}_{1}$ has been estab-

\footnotetext{
Ms Jácome and Dr Marques are affiliated with the Lab 3R - Respiratory Research and Rehabilitation Laboratory, School of Health Sciences, and Dr Marques is also affiliated with the Center for Health Technology and Services Research (CINTESIS), School of Health Sciences, University of Aveiro, Aveiro, Portugal. Ms Jácome is also affiliated with the Research Centre in Physical Activity, Health and Leisure (CIAFEL), Faculty of Sports, University of Porto, Porto, Portugal.
}

This study was supported by the Fundação para a Ciência e Tecnologia lished as the global marker for COPD diagnosis and monitoring. ${ }^{1}$ Nevertheless, changes in $\mathrm{FEV}_{1}$ in response to treatment are small in relation to its repeatability. ${ }^{2,3} \mathrm{New}$ clinical markers are therefore needed to evaluate the ef-

\footnotetext{
(FCT SFRH/BD/84665/2012), Portugal. The authors have disclosed no conflicts of interest.

Correspondence: Alda Marques PT MSc PhD, Lab 3R - Respiratory Research and Rehabilitation Laboratory, School of Health Sciences, University of Aveiro (ESSUA), Agras do Crasto-Campus Universitário de Santiago, Edifício 30, 3810-193 Aveiro, Portugal. E-mail: amarques@ua.pt.
}

DOI: $10.4187 /$ respcare.03922 
fectiveness of treatments for COPD ${ }^{4}$ These markers should be simple in terms of measurement, interpretation, and resources used and should have acceptable reliability to ensure that the error involved in measurement is small enough to detect actual changes. ${ }^{4}$

Respiratory sounds are a simple, objective, and noninvasive marker to assess the function of the respiratory system $^{5}$ and do not require special resources beyond those typical of a patient-health professional encounter. However, the variation and reliability of this promising marker in patients with COPD are still unknown.

Using computerized auscultation, it has been shown that adventitious respiratory sounds are characterized mainly by inspiratory crackles and expiratory wheezes in stable subjects with COPD. ${ }^{6-9}$ Respiratory sounds have been suggested as useful in diagnosing community-acquired pneumonia in this population. ${ }^{10}$ These studies showed that respiratory sounds may have potential to monitor the respiratory status of subjects with COPD. However, intersubject variability and intra-subject reliability was not explored, hindering the interpretation of actual changes. In addition, respiratory sounds have been recorded without control of subjects' air flows, despite the well-known influence of air flow on respiratory acoustic and breathing patterns. ${ }^{11-13}$

Computerized respiratory sound analysis guidelines recommend recordings with inspiratory and expiratory peak air flows of $1-1.5 \mathrm{~L} / \mathrm{s}$ or $10-15 \%$ of the predicted maximum peak expiratory air flow. ${ }^{14}$ However, it is unknown if the air flow recommended suits the breathing pattern specificities of patients with COPD. It has been shown that breathing patterns of subjects with COPD have reduced complexity compared with healthy subjects, ${ }^{15}$ which may affect respiratory sound reliability at different air flows. Computerized respiratory sound analysis guidelines also standardized 7 anatomic locations (trachea and right and left anterior, lateral, and posterior chest) to record respiratory sounds. ${ }^{14}$ Nevertheless, inter-subject variability and intra-subject reliability of respiratory sounds at each anatomic location in patients with COPD have not been investigated. To address these relevant research needs, this study assessed the (1) intra-subject reliability of breathing patterns and respiratory sounds at distinct air flows and (2) inter-subject variability and intra-subject reliability of respiratory sounds at each standardized anatomic location in subjects with COPD.

\section{Methods}

\section{Study Design}

A 2-part study was conducted. Part 1 assessed the intrasubject reliability of breathing patterns and respiratory

\section{QUICK LOOK}

\section{Current knowledge}

Auscultation of respiratory sounds is a simple, objective, and noninvasive method to evaluate the respiratory system with an inexpensive tool. Using a stethoscope, evaluation of respiratory sounds is subject to operator skill, experience, and inter-observer reliability. Computerized auscultation may offer advantages to conventional auscultation.

\section{What this paper contributes to our knowledge}

Computerized assessment of respiratory sounds was more reliable at an air flow of $0.4-0.6 \mathrm{~L} / \mathrm{s}$ and were highly variable in subjects with COPD. The reliability of respiratory sounds over a set of standardized anatomic locations was very good. The use of these anatomic locations at the target flow range may improve the usefulness of computerized respiratory sound assessments in evaluating disease severity and response to treatment.

sounds at 3 distinct air flows using a small sample of out-patients with COPD. Part 2 characterized the intersubject variability and intra-subject reliability of respiratory sounds at each anatomic location using the most reliable air flow from part 1 and a larger sample of out-patients with COPD.

\section{Participants}

Out-patients with COPD were recruited from 2 primary care centers. Inclusion criteria were diagnosis of COPD according to the Global Initiative for Chronic Obstructive Lung Disease (GOLD) criteria (presence of a post-bronchodilator $\left.\mathrm{FEV}_{1} / \mathrm{FVC}<0.70\right)^{1}$ and clinical stability for 1 month before the study (no hospital admissions, exacerbations as defined by GOLD, or changes in respiratory system medication). Subjects were excluded if they had coexisting respiratory diseases or severe neurological, musculoskeletal, or psychiatric impairments. Approval for this study was obtained from the ethics committee of the Center Health Regional Administration (2013-05-02) and from the National Data Protection Committee (3292/2013). Eligible subjects were identified by clinicians and then contacted by the researchers, who explained the purpose of the study and asked about their willingness to participate. When subjects agreed to participate, an appointment with the researchers was scheduled. Written informed consent was obtained before data collection. 


\section{Respiratory Sounds Are Reliable in Subjects With COPD}

\section{Data Collection}

Sociodemographic, anthropometric (height and weight), and clinical (smoking habits, dyspnea, exacerbations in the past 3 months and in the previous year, medication) data were first recorded in the 2 study parts. Air flows and respiratory sounds were recorded. Lung function was assessed by spirometry (MicroLab 3500, CareFusion, Kent, United Kingdom) according to standardized guidelines. ${ }^{16}$ Subjects were classified into 4 groups (A-D) using the GOLD combined assessment (Modified Medical Research Council scale, spirometry, and exacerbation risk). ${ }^{1}$ All assessments were performed by 2 physiotherapists, and the order was standardized.

Part 1. Air flows and respiratory sounds were acquired simultaneously. Recordings were performed at spontaneous air flow, at a peak of $0.4-0.6 \mathrm{~L} / \mathrm{s}$ (typical tidal airflow range), and at a peak of $0.7-1 \mathrm{~L} / \mathrm{s}$ (modestly increased air flow). Similar target air flows have been used in previous research. ${ }^{17}$ After 5 min of quiet sitting, the 3 distinct air flows were acquired following the standardized order: spontaneous, $0.4-0.6 \mathrm{~L} / \mathrm{s}$, and $0.7-1 \mathrm{~L} / \mathrm{s}$. Spontaneous breathing was tested first so that it would not be influenced by the target air flows, and the order of the 2 target air flows was selected based on increased air-flow demand. Subjects were seated upright, wearing a nose clip, and breathing through a mouthpiece connected to a heated pneumotachograph (3830, Hans Rudolph, Shawnee, Kansas). For each air flow, subjects performed 3 trials of $20 \mathrm{~s}$ each, ${ }^{18}$ followed by a 2 -min recovery period. During spontaneous air flow, subjects were instructed to breathe normally, and biofeedback of the flow signal was not presented. During target flows, subjects had visual biofeedback of the flow signal (RSS 100R research pneumotach instrumentation system, Hans Rudolph) and were instructed to maintain the flow between 2 horizontal lines. The recording of each target flow was preceded by a training phase of at least 3 breathing cycles.

Respiratory sound recordings followed computerized respiratory sound analysis guidelines for short-term acquisitions ${ }^{14}$ and were performed simultaneously at 7 anatomic locations (trachea and right and left anterior, lateral, and posterior chest) using the LungSounds@UA interface. ${ }^{19}$ Seven stethoscopes (Littmann Classic II S.E., 3M, St Paul, Minnesota) with a microphone (frequency response between 20 and $19 \mathrm{kHz}$; TOM-1545P-R, Projects Unlimited, Dayton, Ohio) and a preamplifier circuit (Intelligent Sensing Anywhere, Coimbra, Portugal) in the main tube were attached to the subject's skin with soft cloth surgical tape $(3 \mathrm{M})$. The analog sound signals were further amplified and converted to digital by an audio interface (ProFire 2626, M-Audio, Cumberland, Rhode Island). The signal was con- verted with a 24-bit resolution at a sampling rate of $44.1 \mathrm{kHz}$ and recorded in WAV format.

Part 2. Air flows and respiratory sounds were acquired simultaneously at the most reliable air flow identified in part 1 . The same procedures from part 1 were followed.

\section{Signal Processing}

All files were processed using algorithms written in MATLAB R2009a (MathWorks, Natick, Massachusetts). Breathing phases were automatically detected using the positive and negative air-flow signals. Mean inspiratory and expiratory times were then calculated. The mean air flows and tidal volumes $\left(\mathrm{V}_{\mathrm{T}}\right)$ were calculated per breathing phase using flow and volume raw signals. To combine the detected breathing phases with sound signals, the flow signals were time-synchronized with tracheal sound signals. Due to the simultaneous acquisition of respiratory sounds at the 7 locations, the breathing phases detected with tracheal sounds were applied to the other 6 locations.

Crackles were detected using a multi-algorithm technique based on established algorithms. ${ }^{20-22}$ This multi-algorithm technique showed a $7 \%$ performance improvement over the best individual algorithm. ${ }^{23}$ Wheezes were detected using an algorithm based on time-frequency analysis. ${ }^{24}$ The mean number of crackles and wheezes per breathing phase was extracted. After excluding these adventitious sounds, normal respiratory sounds were analyzed based on the methodology proposed by Pasterkamp et al, ${ }^{25}$ and the mean intensity was determined within a frequency band of $100-2,000 \mathrm{~Hz} \cdot{ }^{25,26}$

\section{Statistical Analysis}

All statistical analyses were performed using SPSS 20.0 (IBM, Armonk, New York). The level of significance was set at .05 .

Part 1. Descriptive statistics were used to characterize the sample. Mean inspiratory and expiratory air flows, $\mathrm{V}_{\mathrm{T}}$, and time were determined by computing the mean of the 3 recordings at each air flow. The mean normal respiratory sound intensity and mean number of crackles and wheezes per breathing phase were determined by computing the mean of the 3 recordings at all anatomic locations. Oneway repeated-measures analysis of variance was used to analyze differences in breathing patterns and respiratory sounds across air flows. When a statistically significant difference was found, Bonferroni post hoc tests were performed. Statistical analysis was completed with the estimation of effect sizes. The effect size was computed via partial eta-square, as it is the index more commonly reported for analysis of variance. ${ }^{27}$ Partial eta-square was 


\section{Respiratory Sounds Are Reliable in Subjects With COPD}

interpreted as a small ( $\geq 0.01)$, medium $(\geq 0.06)$, or large $(\geq 0.14)$ effect. ${ }^{28}$

As recommended for intra-subject reliability, ${ }^{29}$ both relative reliability (intraclass correlation coefficient [ICC]) and absolute reliability (Bland-Altman method) were used. The ICC equation $(1, \mathrm{k})$ was used, where $\mathrm{k}=3$ because 3 recordings were performed for each air flow. ICC was interpreted as excellent $(>0.75)$, moderate to good $(0.4-$ $0.75)$, or poor $(<0.4) .{ }^{30}$ The Bland-Altman method assesses the agreement between 2 sets of measures. ${ }^{31}$ Thus, random numbers were generated in MATLAB to delete one recording. Bland-Altman plots were created to analyze the distribution of results (Prism 5.01, GraphPad Software, La Jolla, California). ${ }^{31}$

Sample size was determined as described by Bonett. ${ }^{32} \mathrm{~A}$ sample size of 13 subjects was required to estimate an ICC of 0.9 with a $95 \%$ CI width of $0.2(\alpha=.05$ and $\mathrm{k}=3){ }^{32}$

Part 2. Descriptive statistics were used to characterize the sample. The mean normal respiratory sound intensity and mean number of crackles and wheezes per breathing phase were determined by computing the mean of the 3 recordings for each anatomic location (trachea and right and left anterior, lateral, and posterior chest). The intersubject variability in respiratory sound parameters was measured with the coefficient of variation, as it is useful for analyzing the variability of measures independently of the magnitude of the data. ${ }^{33}$ It is defined as the SD divided by the mean. ${ }^{34}$ The relative and absolute intra-subject reliability of respiratory sound parameters were computed, as described above, per anatomic location.

Sample size for the coefficient of variation was estimated using the approach of Kelley. ${ }^{35}$ Using data from part 1, we found that the coefficient of variation for normal respiratory sound intensity was between 0.17 and 0.25 . We determined that a minimum of 59 individuals were needed for a coefficient of variation of 0.25 with a $95 \%$ CI width of $0.1(\alpha=.05) .^{35}$

\section{Results}

\section{Part 1}

Thirteen subjects (10 males) were enrolled. Four subjects had mild air-flow limitation, 6 had moderate, and 3 had severe-to-very-severe air-flow limitation. All subjects used long-acting bronchodilators. Table 1 lists subjects' characteristics.

Respiratory Sounds. The intensity of normal respiratory sounds during inspiration and expiration was higher at an air flow of $0.7-1 \mathrm{~L} / \mathrm{s}$ (post hoc $P<.001$ ) (Table 2). No significant differences were seen in the mean number of crackles (inspiratory, $P=.45$; expiratory, $P=.066$ ) and
Table 1. Sociodemographic, Anthropometric, and Clinical Characteristics of Subjects

\begin{tabular}{lc}
\hline \hline \multicolumn{1}{c}{ Characteristic } & Values \\
\hline Age, mean \pm SD y & $69.3 \pm 8.6$ \\
Males/females, $n$ & $10 / 3$ \\
Current smokers, $n$ & 0 \\
mMRC scale, median (IQR) & $1(1-2)$ \\
BMI, mean \pm SD kg/m ${ }^{2}$ & $29.5 \pm 3.4$ \\
Exacerbations in past 3 m, $n$ & \\
0 & 5 \\
1 & 6 \\
$\geq 2$ & 2 \\
FEV ${ }_{1}$, mean \pm SD L & $1.8 \pm 0.6$ \\
FEV, mean \pm SD $\%$ predicted & $70.9 \pm 21.4$ \\
FEV ${ }_{1} /$ FVC, mean \pm SD & $0.66 \pm 0.09$ \\
GOLD air-flow limitation, $n$ & \\
Mild & 4 \\
Moderate & 6 \\
Severe to very severe & 3 \\
GOLD combined assessment, $n$ & \\
A: low risk, fewer symptoms & 3 \\
B: low risk, more symptoms & \\
C: high risk, fewer symptoms & \\
D: high risk, more symptoms & \\
& \\
\hline$N=13$. & \\
mMRC $=$ modified Medical Research Council & \\
QQR $=$ interquartile range \\
BMI $=$ body mass index \\
GOLD = Global Initiative for Chronic Obstructive Lung Disease \\
\hline
\end{tabular}

wheezes (inspiratory, $P=.30$; expiratory, $P=.12$ ). The relative reliability of normal respiratory sound intensity was moderate to excellent at the 3 air flows (see Table 2). Bland-Altman plots indicated greater agreement for normal respiratory sound intensity at an air flow of 0.4 $0.6 \mathrm{~L} / \mathrm{s}$ (Figs. 1B and 2B). The relative reliability of the mean number of inspiratory and expiratory crackles was found to be moderate to excellent at the 3 air flows (see Table 2). However, a higher level of agreement existed at an air flow of $0.4-0.6 \mathrm{~L} / \mathrm{s}$, with narrower limits of agreement (Figs. 1E and 2E). The relative reliability of the mean number of inspiratory and expiratory wheezes was excellent at all air flows (see Table 2), although greater agreement was found at target air flows (Figs. 1H and 1I and $2 \mathrm{H}$ and $2 \mathrm{I}$ ).

Breathing Pattern. At an air flow of $0.7-1 \mathrm{~L} / \mathrm{s}$, significantly higher flows (post hoc $P<.001$ ) and $\mathrm{V}_{\mathrm{T}}$ (post hoc $P<.05$ ) were found (see Table 2). Inspiratory and expiratory times were similar across air flows $(P=.6$ and .21 , respectively). Intra-subject relative reliability of air flow, $\mathrm{V}_{\mathrm{T}}$, and time were higher at a target air flow of $0.4-$ $0.6 \mathrm{~L} / \mathrm{s}$ (ICC of 0.73-0.95) compared with spontaneous air flow (ICC of $0.60-0.88$ ) or a target air flow of $0.7-1 \mathrm{~L} / \mathrm{s}$ 


\section{Respiratory Sounds Are Reliable in Subjects With COPD}

Table 2. Descriptive Characteristics and Intra-Subject Relative Reliability of Respiratory Sounds and Breathing Pattern Parameters at 3 Air Flows

\begin{tabular}{|c|c|c|c|c|c|c|c|c|}
\hline \multirow{2}{*}{ Characteristic } & \multicolumn{2}{|c|}{ Spontaneous Air Flow } & \multicolumn{2}{|c|}{ Air Flow of $0.4-0.6 \mathrm{~L} / \mathrm{s}$} & \multicolumn{2}{|c|}{ Air Flow of $0.7-1 \mathrm{~L} / \mathrm{s}$} & \multirow[b]{2}{*}{$P$} & \multirow[b]{2}{*}{$\begin{array}{c}\text { Partial } \\
\text { Eta-Square }\end{array}$} \\
\hline & $($ mean $\pm \mathrm{SD})$ & ICC $(95 \% \mathrm{CI})$ & $($ mean $\pm \mathrm{SD})$ & ICC $(95 \% \mathrm{CI})$ & $($ mean $\pm \mathrm{SD})$ & $\mathrm{ICC}(95 \% \mathrm{CI})$ & & \\
\hline $\begin{array}{l}\text { Inspiratory normal } \\
\text { respiratory sound } \\
\text { intensity, dB }\end{array}$ & $11.8 \pm 2.16$ & $0.74(0.35-0.91)$ & $11.32 \pm 1.88$ & $0.88(0.7-0.96)$ & $12.98 \pm 2.33$ & $0.89(0.73-0.96)$ & $<.001$ & 0.634 \\
\hline $\begin{array}{l}\text { Expiratory normal } \\
\text { respiratory sound } \\
\text { intensity, } \mathrm{dB}\end{array}$ & $10.49 \pm 2.05$ & $0.66(0.14-0.89)$ & $10.30 \pm 1.82$ & $0.65(0.13-0.88)$ & $12.06 \pm 2.96$ & $0.74(0.36-0.91)$ & $<.001$ & 0.757 \\
\hline $\begin{array}{l}\text { Crackles on } \\
\text { inspiration }\end{array}$ & $1.57 \pm 0.78$ & $0.75(0.38-0.92)$ & $1.30 \pm 0.60$ & $0.71(0.27-0.90)$ & $1.38 \pm 0.50$ & $0.81(0.52-0.94)$ & .45 & 0.064 \\
\hline Crackles on expiration & $2.49 \pm 1.35$ & $0.78(0.44-0.93)$ & $1.47 \pm 1.05$ & $0.89(0.74-0.97)$ & $1.34 \pm 0.64$ & $0.75(0.39-0.92)$ & .066 & 0.203 \\
\hline $\begin{array}{l}\text { Wheezes on } \\
\text { inspiration }\end{array}$ & $0.35 \pm 0.49$ & $0.79(0.46-0.93)$ & $0.31 \pm 0.55$ & $0.78(0.46-0.93)$ & $0.25 \pm 0.31$ & $0.75(0.37-0.92)$ & .30 & 0.096 \\
\hline Wheezes on expiration & $0.59 \pm 0.91$ & $0.89(0.72-0.96)$ & $0.72 \pm 1.72$ & $0.99(0.96-0.99)$ & $0.30 \pm 0.39$ & $0.78(0.46-0.93)$ & .12 & 0.161 \\
\hline Inspiratory flow, L/s & $0.38 \pm 0.18$ & $0.73(0.32-0.91)$ & $0.44 \pm 0.14$ & $0.95(0.88-0.98)$ & $0.7 \pm 0.11$ & $0.74(0.34-0.91)$ & $<.001$ & 0.648 \\
\hline Expiratory flow, L/s & $0.30 \pm 0.17$ & $0.88(0.70-0.96)$ & $0.33 \pm 0.09$ & $0.92(0.81-0.97)$ & $0.60 \pm 0.09$ & $0.77(0.42-0.92)$ & $<.001$ & 0.751 \\
\hline Inspiratory $\mathrm{V}_{\mathrm{T}}, \mathrm{L}$ & $0.54 \pm 0.18$ & $0.76(0.37-0.93)$ & $0.57 \pm 0.1$ & $0.85(0.63-0.95)$ & $0.96 \pm 0.22$ & $0.84(0.61-0.95)$ & .001 & 0.431 \\
\hline Expiratory $\mathrm{V}_{\mathrm{T}}, \mathrm{L}$ & $0.56 \pm 0.25$ & $0.60(0.01-0.87)$ & $0.56 \pm 0.11$ & $0.73(0.31-0.91)$ & $0.95 \pm 0.24$ & $0.70(0.25-0.90)$ & .001 & 0.525 \\
\hline $\mathrm{T}_{\mathrm{I}}, \mathrm{s}$ & $1.36 \pm 0.41$ & $0.64(0.02-0.89)$ & $1.15 \pm 0.28$ & $0.85(0.60-0.96)$ & $1.24 \pm 0.34$ & $0.84(0.59-0.95)$ & .60 & 0.097 \\
\hline TE, s & $1.81 \pm 0.53$ & $0.72(0.29-0.91)$ & $1.71 \pm 0.85$ & $0.80(0.50-0.93)$ & $1.50 \pm 0.40$ & $0.77(0.42-0.92)$ & .21 & 0.123 \\
\hline \multicolumn{9}{|c|}{$\begin{array}{l}=13 . \\
\text { ICC }=\text { intraclass correlation coefficient } \\
\mathrm{V}_{\mathrm{T}}=\text { tidal volume } \\
\mathrm{T}_{\mathrm{I}}=\text { inspiratory time } \\
\mathrm{T}_{\mathrm{E}}=\text { expiratory time }\end{array}$} \\
\hline
\end{tabular}
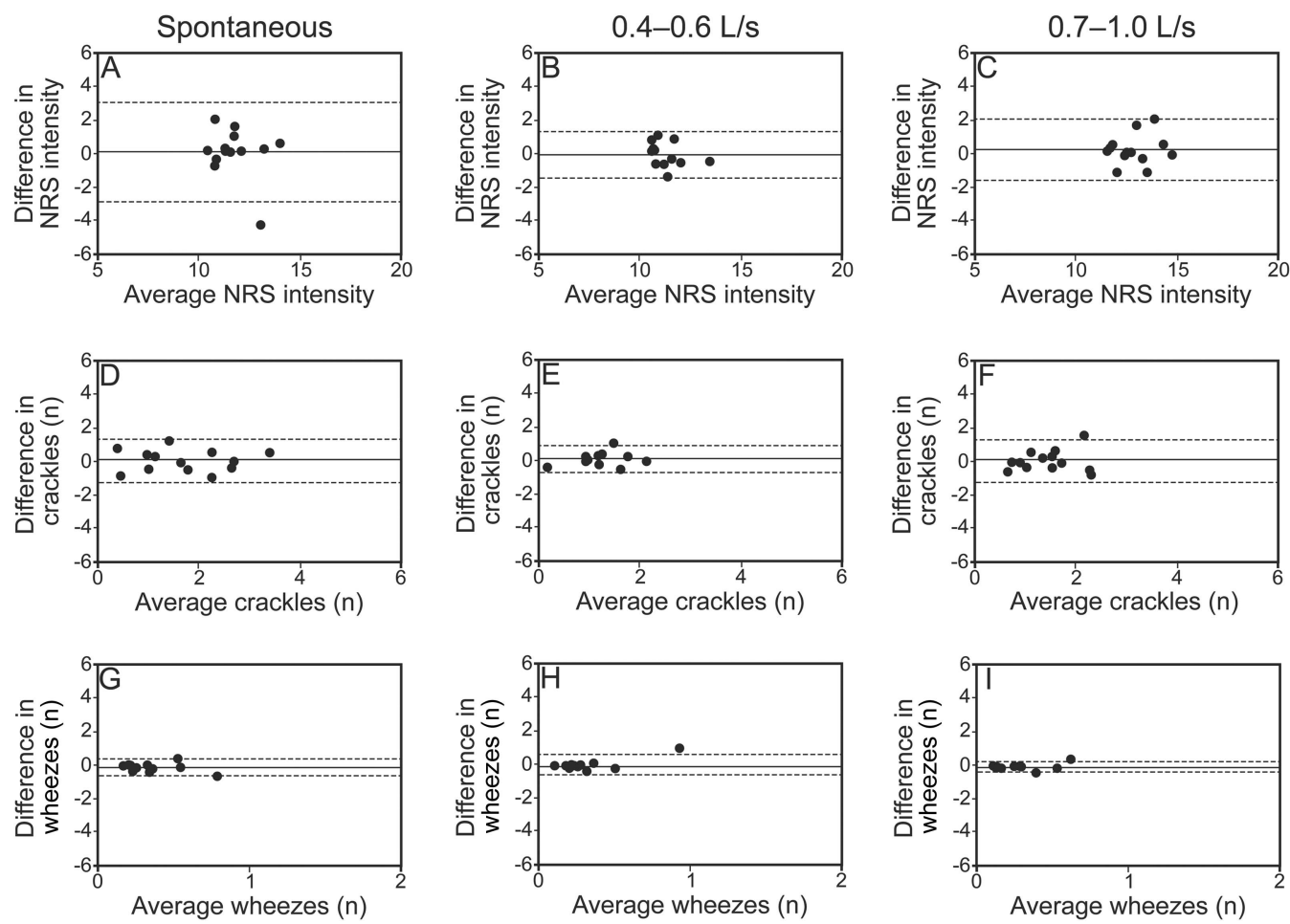

Fig. 1. Bland-Altman plots of inspiratory normal respiratory sound (NRS) intensity and mean number of crackles and wheezes between 2 recordings at 3 distinct air flows: spontaneous, 0.4-0.6 L/s, and 0.7-1.0 L/s. The solid lines represent the mean difference, and the dashed lines show the $95 \%$ limits of agreement. 



Fig. 2. Bland-Altman plots of expiratory normal respiratory sound intensity and mean number of crackles and wheezes between 2 recordings at 3 distinct air flows: spontaneous, $0.4-0.6 \mathrm{~L} / \mathrm{s}$, and 0.7-1.0 L/s. The solid lines represent the mean difference, and the dashed lines show the $95 \%$ limits of agreement.

(ICC of 0.70-0.84) (see Table 2). Figures 3 and 4 show that intra-subject absolute reliability was higher at $0.4-$ $0.6 \mathrm{~L} / \mathrm{s}$. From analysis of respiratory sound and breathing pattern parameters, it was verified that intra-subject reliability was higher at an air flow of $0.4-0.6 \mathrm{~L} / \mathrm{s}$.

\section{Part 2}

A total of 63 subjects (48 males) were enrolled. Most participants had low risk of exacerbations (A, 34.9\%; B, $36.5 \%$ ), and all used long-acting bronchodilators. Table 3 provides subjects' detailed characteristics.

Respiratory Sounds. Descriptive characteristics of normal respiratory sound intensity (from 9.41 to $14.71 \mathrm{~dB}$ ), mean number of crackles (from 1.43 to 3.46 ), and mean number of wheezes (from 0.06 to 0.40 ) across locations are presented in Table 4. Inter-subject variability was high for all respiratory sound parameters; however, the mean number of crackles (coefficient of variation of $0.55-0.92$ ) and wheezes (coefficient of variation of 1.15-2.22) presented the highest variation. Inter-subject variability was generally higher during expiration than inspiration for all respiratory sound parameters (normal respiratory sound intensity of $0.12-0.23$ vs $0.15-0.21$, mean number of crack- les of $0.56-0.92$ vs $0.55-0.78$, mean number of wheezes of $1.36-2.22$ vs $1.2-2.17$ ) at most locations, with the exception of the trachea.

Normal respiratory sound intensity had an excellent relative and absolute reliability at all anatomic locations (see Table 4). The relative and absolute reliability of the mean number of crackles and wheezes were moderate to excellent at all anatomic locations. The only exceptions were the mean number of inspiratory and expiratory crackles at the trachea, which showed poor relative and absolute reliability.

\section{Discussion}

To the best of our knowledge, this is the first study investigating inter-subject variability and intra-subject reliability of respiratory sounds at distinct air flows and anatomic locations in subjects with stable COPD. The main findings indicated that respiratory sound parameters are (1) more reliable at an air flow of $0.4-0.6 \mathrm{~L} / \mathrm{s}$, (2) highly variable across subjects, and (3) reliable overall at all standardized anatomic locations.

The normal respiratory sound intensity increased at higher air flows. The link between sound intensity and air flow has long been recognized. ${ }^{36}$ From spontaneous to 

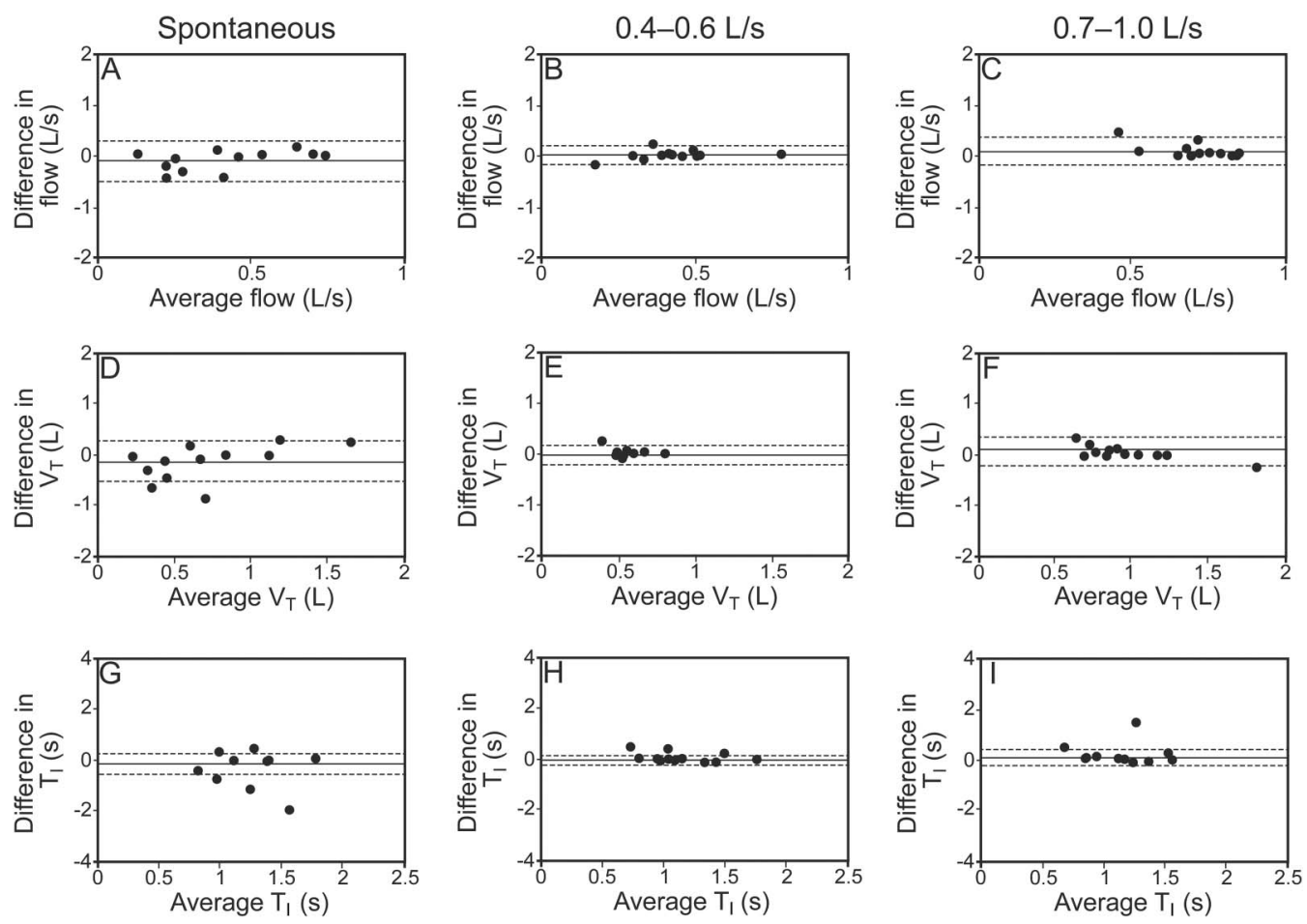

Fig. 3. Bland-Altman plots of inspiratory air flow, volume, and time between 2 recordings at 3 distinct air flows: spontaneous, $0.4-0.6 \mathrm{~L} / \mathrm{s}$, and $0.7-1.0 \mathrm{~L} / \mathrm{s}$. The solid lines represent the mean difference, and the dashed lines show the $95 \%$ limits of agreement. $\mathrm{V}_{\mathrm{T}}=$ tidal volume; $\mathrm{T}_{1}=$ inspiratory time.


Fig. 4. Bland-Altman plots of expiratory air flow, volume, and time between 2 recordings at 3 distinct air flows: spontaneous, $0.4-0.6$ L/s, and $0.7-1.0 \mathrm{~L} / \mathrm{s}$. The solid lines represent the mean difference, and the dashed lines show the $95 \%$ limits of agreement. $\mathrm{V}_{\mathrm{T}}=$ tidal volume; $\mathrm{T}_{\mathrm{E}}=$ expiratory time. 


\section{Respiratory Sounds Are Reliable in Subjects With COPD}

Table 3. Sociodemographic, Anthropometric, and Clinical Characteristics of Subjects

\begin{tabular}{lc}
\hline \multicolumn{1}{c}{ Characteristic } & Values \\
\hline Age, mean \pm SD y & $67.3 \pm 10.4$ \\
Males/females, $n$ & $48 / 15$ \\
Current smokers, $n(\%)$ & $16(25.4)$ \\
mMRC scale, median (IQR) & $1(1-2)$ \\
BMI, mean \pm SD kg/m ${ }^{2}$ & $29 \pm 5$ \\
Exacerbations in past 3 m, $n(\%)$ & \\
0 & $35(55.6)$ \\
1 & $17(27)$ \\
$\geq 2$ & $11(17.4)$ \\
FEV ${ }_{1}$, mean \pm SD L & $1.9 \pm 0.6$ \\
FEV ${ }_{1}$, mean \pm SD $\%$ predicted & $75.4 \pm 22.9$ \\
FEV ${ }_{1} /$ FVC, mean \pm SD & $0.65 \pm 0.09$ \\
GOLD air-flow limitation, $n(\%)$ & \\
Mild & $35(55.6)$ \\
Moderate & $22(34.9)$ \\
Severe to very severe & $6(9.5)$ \\
GOLD combined assessment, $n(\%)$ & \\
A: low risk, fewer symptoms & $22(34.9)$ \\
B: low risk, more symptoms & $23(36.5)$ \\
C: high risk, fewer symptoms & $8(12.7)$ \\
D: high risk, more symptoms & $10(15.9)$ \\
& \\
\hline$N=63$. & \\
mMRC $=$ modified British Medical Research Council & \\
BQR $=$ interquartile range & \\
GOLD $=$ Global Initiative for Chronic Obstructive Lung Disease. & \\
\hline
\end{tabular}

target air flows, the mean number of inspiratory and expiratory crackles had a tendency to decrease. This has also been observed in subjects with interstitial pulmonary fibrosis when comparing crackle rate during normal and deep-breathing maneuvers. ${ }^{37}$ This may be related to the effect of lung expansion, as recordings were repeated at short intervals. ${ }^{38}$ During the first breathing maneuvers, regions of deflated airways probably opened, and in the following maneuvers, the production of crackles decreased. ${ }^{38}$ The mean number of wheezes also had a tendency to decrease. The consecutive expirations at increased air flows could have been sufficient to decrease the crosssectional diameter of airways (particularly of the second generation of the airway tree), ${ }^{5}$ increase linear velocities, and aid secretion movement. ${ }^{39}$ This phenomenon could have reduced the narrowing airway and thus the production of wheezes. ${ }^{5,40}$ These findings show that the characteristics of respiratory sounds are variable at distinct air flows, reinforcing the need to use standardized air flows during computerized auscultation. This will be essential if respiratory sounds are to become a clinical marker to evaluate the effectiveness of treatments.

The relative reliability of normal respiratory sound intensity and of the mean number of crackles was moderate to excellent at the 3 air flows. However, ICCs in isolation do not provide a true picture of reliability. ${ }^{29}$ The BlandAltman method is independent of the true variability and provides detail regarding the nature of the observed intrasubject variability. ${ }^{29}$ The agreement assessed with the Bland-Altman method was found to be acceptable for normal respiratory sound intensity and mean number of crackles at the 3 air flows. Nevertheless, for these respiratory sound parameters, a higher agreement was found at an air flow of $0.4-0.6 \mathrm{~L} / \mathrm{s}$. The reliability of the mean number of wheezes was excellent at all air flows. Forced expiratory wheezes have also been found to be reproducible in healthy subjects. ${ }^{41}$ No systematic bias was observed at any tested air flow, although a higher agreement was found at target air flows.

Regarding breathing pattern, the mean inspiratory $(0.38 \pm 0.18 \mathrm{~L} / \mathrm{s})$ and expiratory $(0.3 \pm 0.17 \mathrm{~L} / \mathrm{s})$ flows at spontaneous air flow were similar to values reported previously. ${ }^{42-44}$ Significantly higher $\mathrm{V}_{\mathrm{T}}$ was observed at air flows of $0.7-1 \mathrm{~L} / \mathrm{s}$, which was expected due to the direct relationship between air flow and volume. ${ }^{45}$ Inspiratory $(1.15-1.36 \mathrm{~s})$ and expiratory $(1.50-1.81 \mathrm{~s})$ times were within commonly reported values in the literature. ${ }^{46} \mathrm{In}$ subjects with COPD, the breathing pattern has also been found to be similar during constant and incremental loaded breathing tests. ${ }^{46}$ The intra-subject reliability of breathing pattern parameters was found to be better at target air flows. ${ }^{47}$ This might be due to the explicit instructions to breathe at a typical peak air flow, which further reduced the breathing complexity. ${ }^{15}$ In accordance with this, breathing pattern was also more reliable at target flows, especially at an air flow of $0.4-0.6 \mathrm{~L} / \mathrm{s}$. This is probably explained by the fact that an air flow of $0.7-1 \mathrm{~L} / \mathrm{s}$ was the most demanding for subjects to perform and maintain during the 20-s recordings. ${ }^{47}$ Therefore, from analysis of respiratory sound and breathing pattern parameters, it can be concluded that a target air flow of $0.4-0.6 \mathrm{~L} / \mathrm{s}$ is the most reliable for characterizing normal respiratory sounds, crackles, and wheezes in subjects with COPD.

At an air flow of $0.4-0.6 \mathrm{~L} / \mathrm{s}$, the normal respiratory sound intensity across locations was found to be 9.41$14.71 \mathrm{~dB}$. These values are slightly lower than those found for healthy subjects at the right posterior chest (inspiration of $17.17 \mathrm{~dB}$, expiration of $11.50 \mathrm{~dB}){ }^{48}$ Nevertheless, in this previous study, healthy subjects breathed at a higher target flow $(1.5 \pm 0.2 \mathrm{~L} / \mathrm{s})$. The mean number of crackles was $1.43-3.46$, within the previously described range $(0.73-$ 5). ${ }^{8,49}$ Wheezes were not frequent across locations (from 0.06 to 0.40 ), which is in line with a previous study. ${ }^{8}$

Nevertheless, even when recorded at the most reliable air flow, respiratory sound parameters exhibited considerable inter-subject variability. Among other factors, differences regarding demographic, anthropometric, and clinical (eg, dyspnea, COPD severity, and history of exacerba- 


\section{Respiratory Sounds Are Reliable in Subjects With COPD}

Table 4. Descriptive Characteristics, Inter-Subject Variability, and Relative and Absolute Reliability of Respiratory Sounds Per Anatomic Location at an Air Flow of $0.4-0.6 \mathrm{~L} / \mathrm{s}$

\begin{tabular}{|c|c|c|c|c|c|}
\hline $\begin{array}{l}\text { Characteristic and } \\
\text { Anatomic Location }\end{array}$ & Mean \pm SD & $\begin{array}{l}\text { Coefficient of } \\
\text { Variation }\end{array}$ & $\mathrm{ICC}(95 \% \mathrm{CI})$ & $\begin{array}{c}\text { Mean } \\
\text { Difference } \pm \mathrm{SD}\end{array}$ & $\begin{array}{l}95 \% \text { Limits } \\
\text { of Agreement }\end{array}$ \\
\hline \multicolumn{6}{|c|}{$\begin{array}{l}\text { Inspiratory normal respiratory sound } \\
\text { intensity, } \mathrm{dB}\end{array}$} \\
\hline Trachea & $12.94 \pm 3.67$ & 0.28 & $0.95(0.92-0.97)$ & $-0.28 \pm 1.22$ & -2.68 to 2.12 \\
\hline Anterior right chest & $12.43 \pm 2.00$ & 0.16 & $0.90(0.85-0.94)$ & $0.18 \pm 0.91$ & -1.62 to 1.97 \\
\hline Anterior left chest & $10.43 \pm 1.59$ & 0.15 & $0.93(0.89-0.95)$ & $-0.12 \pm 0.99$ & $-2.07-1.83$ \\
\hline Lateral right chest & $12.88 \pm 2.73$ & 0.21 & $0.93(0.89-0.96)$ & $0.28 \pm 1.48$ & $-2.61-3.18$ \\
\hline Lateral left chest & $13.65 \pm 2.83$ & 0.21 & $0.88(0.82-0.92)$ & $0.02 \pm 1.69$ & $-3.30-3.33$ \\
\hline Posterior right chest & $14.71 \pm 2.88$ & 0.20 & $0.93(0.89-0.96)$ & $0.16 \pm 0.89$ & $-1.58-1.91$ \\
\hline Posterior left chest & $12.02 \pm 2.25$ & 0.19 & $0.93(0.89-0.96)$ & $0.22 \pm 1.34$ & $-2.40-2.84$ \\
\hline \multicolumn{6}{|c|}{$\begin{array}{l}\text { Expiratory normal respiratory sound } \\
\text { intensity, } \mathrm{dB}\end{array}$} \\
\hline Trachea & $13.20 \pm 3.33$ & 0.25 & $0.93(0.89-0.95)$ & $-0.26 \pm 1.47$ & -3.14 to 2.62 \\
\hline Anterior right chest & $11.16 \pm 1.36$ & 0.12 & $0.88(0.81-0.92)$ & $0.13 \pm 0.92$ & -1.68 to 1.94 \\
\hline Anterior left chest & $9.41 \pm 1.20$ & 0.13 & $0.91(0.86-0.94)$ & $-0.08 \pm 0.80$ & -1.65 to 1.49 \\
\hline Lateral right chest & $11.68 \pm 2.42$ & 0.21 & $0.94(0.90-0.96)$ & $-0.07 \pm 1.63$ & -3.26 to 3.11 \\
\hline Lateral left chest & $12.58 \pm 2.90$ & 0.23 & $0.88(0.81-0.92)$ & $-0.38 \pm 1.63$ & -3.58 to 2.81 \\
\hline Posterior right chest & $12.96 \pm 2.83$ & 0.22 & $0.89(0.83-0.93)$ & $0.14 \pm 0.95$ & -1.73 to 2.00 \\
\hline Posterior left chest & $10.69 \pm 2.01$ & 0.19 & $0.87(0.81-0.92)$ & $0.19 \pm 1.66$ & -3.06 to 3.44 \\
\hline \multicolumn{6}{|l|}{ No. of crackles on inspiration } \\
\hline Trachea & $1.45 \pm 0.90$ & 0.62 & $-0.34(-1.19$ to 0.22$)$ & $-1.83 \pm 1.57$ & -4.91 to 1.25 \\
\hline Anterior right chest & $2.07 \pm 1.15$ & 0.55 & $0.79(0.69-0.87)$ & $0.05 \pm 1.17$ & -2.24 to 2.34 \\
\hline Anterior left chest & $1.43 \pm 0.80$ & 0.56 & $0.55(0.32-0.72)$ & $0.15 \pm 0.98$ & -1.77 to 2.06 \\
\hline Lateral right chest & $2.57 \pm 1.61$ & 0.63 & $0.59(0.37-0.74)$ & $0.23 \pm 1.72$ & -3.14 to 3.60 \\
\hline Lateral left chest & $2.24 \pm 1.75$ & 0.78 & $0.73(0.59-0.83)$ & $-0.10 \pm 1.36$ & -2.77 to 2.56 \\
\hline Posterior right chest & $2.86 \pm 1.75$ & 0.61 & $0.77(0.65-0.86)$ & $0.31 \pm 1.54$ & -2.70 to 3.33 \\
\hline Posterior left chest & $2.37 \pm 1.77$ & 0.74 & $0.42(0.08-0.65)$ & $1.45 \pm 1.27$ & -1.03 to 3.93 \\
\hline \multicolumn{6}{|l|}{ No. of crackles on expiration } \\
\hline Trachea & $1.65 \pm 1.11$ & 0.68 & $0.02(-0.61$ to 0.43$)$ & $-1.75 \pm 1.95$ & -5.57 to 2.08 \\
\hline Anterior right chest & $3.07 \pm 1.72$ & 0.56 & $0.78(0.67-0.86)$ & $0.22 \pm 1.47$ & -2.67 to 3.10 \\
\hline Anterior left chest & $2.15 \pm 1.57$ & 0.73 & $0.90(0.85-0.94)$ & $0.25 \pm 1.22$ & -2.14 to 2.64 \\
\hline Lateral right chest & $3.33 \pm 2.30$ & 0.69 & $0.52(0.27-0.7)$ & $-0.38 \pm 2.18$ & -4.65 to 3.89 \\
\hline Lateral left chest & $2.89 \pm 2.06$ & 0.71 & $0.64(0.45-0.77)$ & $-0.13 \pm 1.28$ & -2.64 to 2.38 \\
\hline Posterior right chest & $3.46 \pm 2.80$ & 0.81 & $0.86(0.79-0.91)$ & $0.23 \pm 1.70$ & -3.10 to 3.56 \\
\hline Posterior left chest & $2.99 \pm 2.74$ & 0.92 & $0.57(0.31-0.74)$ & $1.31 \pm 1.24$ & -1.12 to 3.74 \\
\hline \multicolumn{6}{|l|}{ No. of wheezes on inspiration } \\
\hline Trachea & $0.35 \pm 0.47$ & 1.34 & $0.61(0.41-0.75)$ & $0.20 \pm 0.63$ & -1.04 to 1.44 \\
\hline Anterior right chest & $0.16 \pm 0.34$ & 2.17 & $0.87(0.81-0.92)$ & $0.00 \pm 0.18$ & -0.36 to 0.35 \\
\hline Anterior left chest & $0.06 \pm 0.11$ & 1.68 & $0.44(0.15-0.64)$ & $0.05 \pm 0.20$ & -0.33 to 0.43 \\
\hline Lateral right chest & $0.20 \pm 0.30$ & 1.51 & $0.49(0.23-0.68)$ & $-0.01 \pm 0.32$ & -0.64 to 0.61 \\
\hline Lateral left chest & $0.16 \pm 0.20$ & 1.20 & $0.42(0.12-0.63)$ & $0.05 \pm 0.38$ & -0.70 to 0.80 \\
\hline Posterior right chest & $0.18 \pm 0.30$ & 1.65 & $0.80(0.70-0.88)$ & $-0.19 \pm 0.38$ & -0.92 to 0.55 \\
\hline Posterior left chest & $0.21 \pm 0.27$ & 1.27 & $0.35(0.02-0.59)$ & $0.01 \pm 0.30$ & -0.57 to 0.59 \\
\hline \multicolumn{6}{|l|}{ No. of wheezes on expiration } \\
\hline Trachea & $0.37 \pm 0.42$ & 1.15 & $0.63(0.43-0.76)$ & $0.14 \pm 0.55$ & -0.94 to 1.23 \\
\hline Anterior right chest & $0.22 \pm 0.40$ & 1.82 & $0.84(0.75-0.9)$ & $0.03 \pm 0.25$ & -0.47 to 0.53 \\
\hline Anterior left chest & $0.13 \pm 0.28$ & 2.22 & $0.83(0.74-0.89)$ & $0.04 \pm 0.31$ & -0.57 to 0.66 \\
\hline Lateral right chest & $0.40 \pm 0.70$ & 1.75 & $0.67(0.49-0.79)$ & $0.06 \pm 0.38$ & -0.69 to 0.81 \\
\hline Lateral left chest & $0.36 \pm 0.54$ & 1.48 & $0.64(0.46-0.77)$ & $0.02 \pm 0.46$ & -0.88 to 0.93 \\
\hline Posterior right chest & $0.28 \pm 0.39$ & 1.36 & $0.65(0.47-0.7)$ & $-0.08 \pm 0.42$ & -0.90 to 0.73 \\
\hline Posterior left chest & $0.31 \pm 0.53$ & 1.70 & $0.77(0.65-0.85)$ & $0.12 \pm 0.31$ & -0.49 to 0.74 \\
\hline
\end{tabular}

$N=63$.

ICC $=$ intraclass correlation coefficient 


\section{Respiratory Sounds Are Reliable in Subjects With COPD}

tions) characteristics might have contributed to this variability across subjects. High inter-subject variability of respiratory sounds has also been reported previously in subjects with cystic fibrosis and bronchiectasis. ${ }^{50}$ However, this inter-subject variability is similar to other biosignals that support clinical decisions (eg, heart rate variability, electromyography). ${ }^{51,52}$ From a clinical perspective, this inter-subject variability limits inferences at the group level, as respiratory sound patterns may fail to represent patterns seen in individuals. For example, increased wheezing has been recognized as one of the signs of a COPD exacerbation..$^{53}$ Nevertheless, due to the high variability of this respiratory sound parameter, a small increase in the mean number of wheezes may indicate a change in the clinical status for one patient, but not another. This highlights the importance of supporting health-care professionals in clinical decisions in the interpretation of respiratory sound changes at an individual level and in combination with other clinical data.

Normal respiratory sound intensity and mean number of crackles and wheezes were found to be reliable across all anatomic locations. At the trachea, however, the mean number of crackles had poor reliability. This result may be due to low generation of this adventitious sound in this region of the respiratory tract. It has been generally accepted that crackles are generated when an airway opens during inspiration or closes during expiration. ${ }^{38,54}$ Because the trachea is characterized by a large diameter and rigid wall, it is unlikely to open or collapse during tidal breathing.

In addition, normal respiratory sound intensity had lower variability and higher reliability than mean number of crackles and wheezes at all anatomic locations. Normal respiratory sounds are produced when breathing and can be heard during both inspiration and expiration (nearly silent). ${ }^{55}$ Crackles and wheezes are superimposed events on normal respiratory sounds, ${ }^{55}$ and timing may not be perfectly repeatable from breath to breath. Health professionals may thus more confidently rely on changes in normal respiratory sound intensity than mean number of adventitious respiratory sounds.

\section{Study Limitations}

The recording of distinct air flows in the same session and at relatively short intervals may have influenced the results. However, to minimize bias, the order of tests was standardized, and subjects were instructed to rest as needed. Future studies assessing intra-subject reliability could perform the recordings in different sessions within the same day. It would be also interesting in future studies to explore the intra-subject test-retest reliability of respiratory sounds to understand their stability and reliability over time. The present study focused on only one parameter per respiratory sound. Future studies could investigate the reliability of respiratory sounds using other parameters that also have clinical relevance. ${ }^{56}$ Additionally, the unbalanced sample in terms of COPD severity is another limitation of the present study. The samples were composed mainly of subjects with mild and moderate air-flow limitation, and thus, it was not possible to explore how the disease severity related to the variability/reliability of respiratory sound parameters. However, as the breathing pattern at an air flow of $0.4-0.6 \mathrm{~L} / \mathrm{s}$ is similar to that in subjects with advanced $\mathrm{COPD}^{46}$ and air-flow variability is not related to COPD severity, ${ }^{15}$ the disease severity might not play a significant role. Future studies should investigate this, however.

\section{Conclusions}

The main findings suggest that respiratory sound parameters are more reliable at an air flow of $0.4-0.6 \mathrm{~L} / \mathrm{s}$, highly variable across subjects with COPD, and reliable overall at all standardized anatomic locations. In the future, respiratory sounds should be assessed in subjects with COPD using this target air flow and these anatomic locations. More studies are needed to draw definite conclusions on air-flow standards for recording respiratory sounds in subjects with COPD and other respiratory diseases.

\section{ACKNOWLEDGMENTS}

We thank all subjects for participation in this research. We are also very grateful to Ana Oliveira for contributions to data collection and to Cátia Pinho for assistance in data analysis.

\section{REFERENCES}

1. Vestbo J, Hurd SS, Agustí AG, Jones PW, Vogelmeier C, Anzueto A, et al. Global strategy for the diagnosis, management, and prevention of chronic obstructive pulmonary disease: GOLD executive summary. Am J Respir Crit Care Med 2013;187(4):347-365.

2. Zwick RH, Burghuber OC, Dovjak N, Hartl S, Kössler W, Lichtenschopf A, et al. [The effect of one year outpatient pulmonary rehabilitation on patients with COPD]. Wien Klin Wochenschr 2009; 121(5-6):189-195. Article in German.

3. Calverley PM, Boonsawat W, Cseke Z, Zhong N, Peterson S, Olsson $\mathrm{H}$. Maintenance therapy with budesonide and formoterol in chronic obstructive pulmonary disease. Eur Respir J 2003;22(6):912-919.

4. Jones PW, Agusti AG. Outcomes and markers in the assessment of chronic obstructive pulmonary disease. Eur Respir J 2006;27(4):822832 .

5. Bohadana A, Izbicki G, Kraman SS. Fundamentals of lung auscultation. N Engl J Med 2014;370(8):744-751.

6. Munakata M, Ukita H, Doi I, Ohtsuka Y, Masaki Y, Homma Y, Kawakami Y. Spectral and wave-form characteristics of fine and coarse crackles. Thorax 1991;46(9):651-657.

7. Bettencourt PE, Del Bono EA, Spiegelman D, Hertzmark E, Murphy 


\section{Respiratory Sounds Are Reliable in Subjects With COPD}

RL Jr. Clinical utility of chest auscultation in common pulmonarydiseases. Am J Respir Crit Care Med 1994;150(5):1291-1297.

8. Murphy RL Jr. Special articles: in defense of the stethoscope. Respir Care 2008;53(3):355-369.

9. Jácome C, Marques A. Computerized respiratory sounds in patients with COPD: a systematic review. COPD 2015;12(1):104-112.

10. Morillo DS, León Jiménez A, Moreno SA. Computer-aided diagnosis of pneumonia in patients with chronic obstructive pulmonary disease. J Am Med Inform Assoc 2013;20(e1):e111-e117.

11. Kraman SS. The relationship between airflow and lung sound amplitude in normal subjects. Chest 1984;86(2):225-229.

12. Gavriely N, Cugell DW. Airflow effects on amplitude and spectral content of normal breath sounds. J Appl Physiol 1996;80(1):5-13.

13. Benchetrit G. Breathing pattern in humans: diversity and individuality. Respir Physiol 2000;122(2-3):123-129.

14. Rossi M, Sovijärvi AR, Piirilä P, Vannuccini L, Dalmasso F, Vanderschoot J. Environmental and subject conditions and breathing manoeuvres for respiratory sound recordings. Eur Respir Rev 2000; 10(77):611-615.

15. Dames KK, Lopes AJ, de Melo PL. Airflow pattern complexity during resting breathing in patients with COPD: effect of airway obstruction. Respir Physiol Neurobiol 2014;192:39-47.

16. Miller MR, Hankinson J, Brusasco V, Burgos F, Casaburi R, Coates A, et al. Standardisation of spirometry. Eur Respir J 2005;26(2):319338.

17. Fiz JA, Gnitecki J, Kraman SS, Wodicka GR, Pasterkamp H. Effect of body position on lung sounds in healthy young men. Chest 2008; 133(3):729-736.

18. Vyshedskiy A, Murphy R. Crackle pitch rises progressively during inspiration in pneumonia, CHF, and IPF patients. Pulm Med 2012; 2012:240160.

19. Pinho C, Oliveira A, Oliveira D, Dinis J, Marques A. LungSounds@UA interface and multimedia database. IJEHMC 2014; 5(1):81-95.

20. Vannuccini L, Rossi M, Pasquali G. A new method to detect crackles in respiratory sounds. Technol Health Care 1998;6(1):75-79.

21. Hadjileontiadis LJ, Rekanos IT. Detection of explosive lung and bowel sounds by means of fractal dimension. IEEE Signal Process Lett 2003;10(10):311-314.

22. Lu X, Bahoura M. An integrated automated system for crackles extraction and classification. Biomed Signal Process Control 2008; 3(3):244-254.

23. Quintas J, Campos G, Marques A. Proceedings of the International Congress on Health Informatics: HEALTHINF 2013 (February 1114, 2013, Barcelona, Spain). Multi-algorithm respiratory crackle detection. SCITEPRESS Digital Library; 239-244.

24. Taplidou SA, Hadjileontiadis LJ. Wheeze detection based on timefrequency analysis of breath sounds. Comput Biol Med 2007;37(8): 1073-1083.

25. Pasterkamp H, Powell RE, Sánchez I. Lung sound spectra at standardized air flow in normal infants, children, and adults. Am J Respir Crit Care Med 1996;154(2 Pt 1):424-430.

26. Sánchez I, Vizcaya C. Tracheal and lung sounds repeatability in normal adults. Respir Med 2003;97(12):1257-1260.

27. Levine TR, Hullett CR. Eta squared, partial eta squared, and misreporting of effect size in communication research. Hum Commun Res 2002;28(4):612-625.

28. Cohen J. Statistical power analysis for the behavioural sciences. New York: Academic Press; 1969.

29. Rankin G, Stokes M. Reliability of assessment tools in rehabilitation: an illustration of appropriate statistical analyses. Clin Rehabil 1998; 12(3):187-199.
30. Fleiss J. Reliability of measurement. In: Fleiss J, editor. Design and analysis of clinical experiments. New York: John Wiley \& Sons, 1986; 1-32.

31. Bland JM, Altman DG. Statistical methods for assessing agreement between two methods of clinical measurement. Lancet 1986;1(8476): 307-310.

32. Bonett DG. Sample size requirements for estimating intraclass correlations with desired precision. Stat Med 2002;21(9):1331-1335.

33. Lovie P. Coefficient of variation. In: Everitt BS, Howell DC, editors. Encyclopedia of statistics in behavioral science. New York: John Wiley \& Sons; 2005; 317-318.

34. Abdi H. Coefficient of variation. In: Salkind NJ, editor. Encyclopedia of research design. Thousand Oaks, CA: SAGE Publications; 2010; 170-172.

35. Kelley K. Sample size planning for the coefficient of variation from the accuracy in parameter estimation approach. Behav Res Methods 2007;39(4):755-766.

36. Ploysongsang Y, Paré JA, Macklem PT. Correlation of regional breath sounds with regional ventilation in emphysema. Am Rev Respir Dis 1982;126(3):526-529.

37. Vyshedskiy A, Ishikawa S, Murphy RL Jr. Crackle pitch and rate do not vary significantly during a single automated-auscultation session in patients with pneumonia, congestive heart failure, or interstitial pulmonary fibrosis. Respir Care 2011;56(6):806-817.

38. Piirilä P, Sovijärvi A. Crackles: recording, analysis and clinical significance. Eur Respir J 1995;8(12):2139-2148.

39. Pavia D, Agnew JE, Lopez-Vidriero MT, Clarke SW. General review of tracheobronchial clearance. Eur J Respir Dis Suppl 1987; 153:123-129.

40. Meslier N, Charbonneau G, Racineux JL. Wheezes. Eur Respir J 1995;8(11):1942-1948.

41. Beck R, Gavriely N. The reproducibility of forced expiratory wheezes. Am Rev Respir Dis 1990;141(6):1418-1422.

42. Dal Negro RW, Turati C, Micheletto C, Menegoni F. Effects of tiotropium and formoterol on quiet breathing pattern assessed by optoelectronic plethysmography in COPD patients: a pilot study. Ther Adv Respir Dis 2012;6(2):97-105.

43. Díaz O, Villafranca C, Ghezzo H, Borzone G, Leiva A, Milic-Emil J, Lisboa C. Role of inspiratory capacity on exercise tolerance in COPD patients with and without tidal expiratory flow limitation at rest. Eur Respir J 2000;16(2):269-275.

44. Díaz O, Villafranca C, Ghezzo H, Borzone G, Leiva A, Milic-Emili $\mathrm{J}$, Lisboa C. Breathing pattern and gas exchange at peak exercise in COPD patients with and without tidal flow limitation at rest. Eur Respir J 2001;17(6):1120-1127.

45. Schlegelmilch R, Kramme R. Pulmonary function testing. In: Kramme R, Hoffmann KP, Pozos R, editors. Springer handbook of medical technology. Berlin: Springer; 2011; 95-117.

46. Hill K, Jenkins SC, Philippe DL, Shepherd KL, Hillman DR, Eastwood PR. Comparison of incremental and constant load tests of inspiratory muscle endurance in COPD. Eur Respir J 2007;30(3): 479-486.

47. Vlemincx E, Van Diest I, Van den Bergh O. Imposing respiratory variability patterns. Appl Psychophysiol Biofeedback 2012;37(3): 153-160.

48. Pasterkamp H, Sánchez I. Effect of gas density on respiratory sounds. Am J Respir Crit Care Med 1996;153(3):1087-1092.

49. Piirilä P, Sovijärvi AR, Kaisla T, Rajala HM, Katila T. Crackles in patients with fibrosing alveolitis, bronchiectasis, COPD, and heart failure. Chest 1991;99(5):1076-1083.

50. Marques A, Bruton A, Barney A. Reliability of lung crackle characteristics in cystic fibrosis and bronchiectasis patients in a clinical setting. Physiol Meas 2009;30(9):903-912. 


\section{Respiratory Sounds Are Reliable in Subjects With COPD}

51. Stockhorst U, Huenig A, Ziegler D, Scherbaum WA. Unconditioned and conditioned effects of intravenous insulin and glucose on heart rate variability in healthy men. Physiol Behav 2011; 103(1):31-38.

52. Lapatki BG, Stegeman DF, Jonas IE. A surface EMG electrode for the simultaneous observation of multiple facial muscles. J Neurosci Methods 2003;123(2):117-128.

53. Sapey E, Stockley RA. COPD exacerbations. 2: aetiology. Thorax 2006;61(3):250-258.
54. Vyshedskiy A, Alhashem RM, Paciej R, Ebril M, Rudman I, Fredberg JJ, Murphy R. Mechanism of inspiratory and expiratory crackles. Chest 2009;135(1):156-164

55. Sovijärvi AR, Dalmasso F, Vanderschoot J, Malmberg LP, Righini G, Stoneman SA. Definition of terms for applications of respiratory sounds. Eur Respir Rev 2000;77(10):597-610.

56. Marques A, Oliveira A, Jácome C. Computerized adventitious respiratory sounds as outcome measures for respiratory therapy: a systematic review. Respir Care 2014;59(5):765-776. 